\title{
ÓLEO DA CASTANHA DE CAJU: OPORTUNIDADES E DESAFIOS NO CONTEXTO DO DESENVOLVIMENTO E SUSTENTABILIDADE INDUSTRIAL
}

\author{
Selma Elaine Mazzetto* e Diego Lomonaco \\ Departamento de Química Orgânica e Inorgânica, Universidade Federal do Ceará, CP 6021, Campus do PICI, 60455-760 Fortaleza - CE, \\ Brasil \\ Giuseppe Mele \\ Dipartimento di Ingegneria dell'Innovazione, Università del Salento, Via Arnesano, 73100, Lecce, Itália
}

Recebido em 15/1/09; aceito em 20/3/09; publicado na web em 7/4/09

\begin{abstract}
CASHEW NUT OIL: OPPORTUNITIES AND CHALLENGES IN THE CONTEXT OF SUSTAINABLE INDUSTRIAL DEVELOPMENT. The new millennium is marked by a growing search for renewable fuels and alternative raw materials from biomass in the petrochemicals industry. However, there are many challenges to overcome regarding technological and human resources aspects. In this scenario, cashew nut oil, which is rich in natural phenols, is considered to be very promising for the development of synthetic and functional products and as a feedstock for production of fine chemicals and a wide variety of new materials.
\end{abstract}

Keywords: cashew nut shell liquid (CNSL); phenolic components; renewable source.

Anacardium occidentale L. é o seu nome científico. Pertencente a família Anacardiaceae, ${ }^{1}$ o cajueiro é uma árvore de aparência exótica, troncos tortuosos, folhas glabras, flores masculinas e hermafroditas e fruto reniforme. Seu pedúnculo superdesenvolvido e muito apreciado pela suculência é frequentemente confundido com o fruto, quando na verdade se trata do pseudofruto, cientificamente denominado de pedúnculo floral, com coloração variante entre o amarelo e o vermelho.

O fruto do cajueiro, popularmente conhecido como castanha de caju, é um aquênio de comprimento e largura variável, casca coriácea lisa, mesocarpo alveolado, repleto de um líquido escuro quase preto, cáustico e inflamável, chamado de líquido da casca da castanha do caju (LCC) ou cashew nut shell liquid (CNSL) como é conhecido internacionalmente. Na parte mais interna da castanha está localizada a amêndoa, constituída de dois cotilédones carnosos e oleosos, que compõem a parte comestível do fruto, revestida por uma película em tons avermelhados (Figura 1).

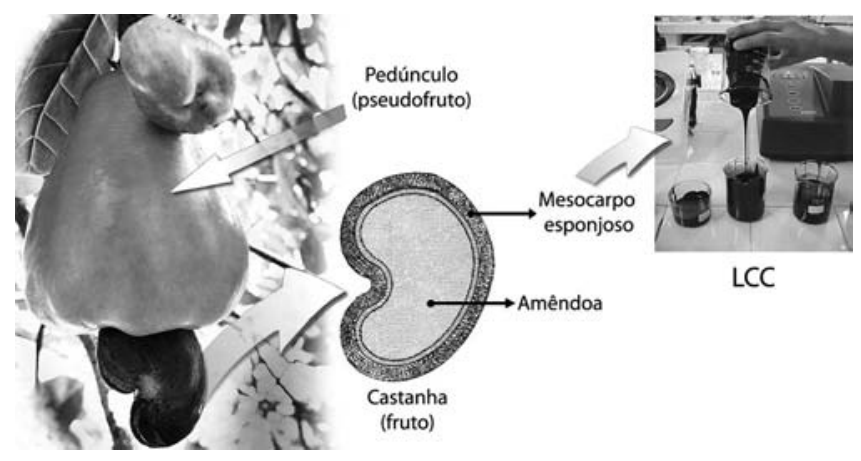

Figura 1. Caju, castanha de caju e LCC

A origem do cajueiro fundamenta-se em provas circunstanciais que indicam, de forma convincente, o Brasil ou pelo menos o norte da América do Sul e parte da América Central como o centro de procedência da espécie cultivada. ${ }^{2} \mathrm{O}$ cajueiro adapta-se melhor às regiões costeiras do nordeste brasileiro, onde faz parte da vegetação de praias e dunas, além das formações de restingas, permitindo supor

*e-mail: selma@ufc.br que a origem filogenética da espécie reside em limítrofes da Mata Amazônica ou cerrados com ecossistemas da região Nordeste, com base na maior diversidade e adaptação da planta nestas localidades.

Um forte indício sobre a origem brasileira do caju está na mais antiga referência conhecida sobre a planta, a ilustração feita pelo monge naturalista francês André Thevet ${ }^{2}$ (1502-1590) em seu livro intitulado Singularidades da França Antártica (Les singularitez de la France Antartique), em 1557, escrito após sua passagem pela costa do Nordeste e Norte do Brasil.

Atualmente, a planta está disseminada em diversos países como Índia, Moçambique, Tanzânia, Quênia e mais recentemente Vietnã, Indonésia e Tailândia. No Brasil, de acordo com o Instituto Brasileiro de Geografia e Estatística - $\mathrm{IBGE}^{3}$ e o Sindicato das Indústrias de Beneficiamento de Castanha de Caju e Amêndoas Vegetais do Estado do Ceará - Sindcaju, ${ }^{4}$ a safra de castanha em 2008 sofreu uma variação de $73 \%$ na produção, e de cerca de $2 \%$ nas áreas plantada e colhida (hectares), mantendo o Ceará como o maior produtor e exportador nacional, seguido por Piauí e Rio Grande do Norte.

As indústrias de beneficiamento da castanha estão concentradas principalmente no estado do Ceará, que detém cerca de $70 \%$ da capacidade instalada da região nordestina. Somente a agroindústria processadora de castanha de caju no Ceará emprega cerca de 20 mil pessoas, além de proporcionar 280 mil postos de trabalho no campo.

O cajueiro tem sido descrito, há séculos, como uma ótima fonte medicinal. ${ }^{1,5}$ No Brasil, há relatos de aplicações como analgésico, diurético, líquido para higiene bucal, tratamento de astenia, problemas respiratórios, gripe, bronquite, tosse, escorbuto infantil, eczema, infecções genitais, sarna, doenças de pele, verrugas e feridas. Do cajueiro, praticamente tudo se aproveita: seu teor de vitamina $\mathrm{C}$ é maior que o da laranja, contém niacina, ${ }^{6}$ uma das vitaminas do complexo B, e ferro sendo seu pedúnculo utilizado na fabricação de sucos, vinhos, licores, doces e compotas.

Por ser rico em fibras também é muito empregado para aumentar a movimentação intestinal. As folhas novas, quando cozidas e colocadas sobre feridas promovem cicatrização. A madeira, muito resistente à água do mar, é empregada na fabricação do cavername de pequenos barcos, na construção civil, confecção de cabos de ferramentas e caixotaria. A casca do tronco contém uma substância 
tintorial vermelho-escuro usada no tingimento de tecidos e redes. Após processamento, a amêndoa pode ser consumida como castanha, torrada, farinha, no preparo de doces, pratos quentes e é exportada para todo o mundo. O mesocarpo produz o LCC, de uso industrial (resinas e freios) e medicinal (antissépticos e vermífugos).

As possibilidades de exploração desta matéria-prima são muitas, porém concentradas em segmentos de baixo valor agregado. $\mathrm{O}$ parque industrial do agronegócio do caju no Brasil é composto por 12 empresas (8 no Ceará, 3 no Rio Grande do Norte e 1 no Piauí) e concentra-se na exportação da amêndoa de castanha de caju (ACC). Juntas, essas empresas têm capacidade de processar até 360 mil toneladas/ano de castanha, gerando 70 mil toneladas de amêndoas e 45 mil toneladas de LCC por ano.

Entretanto, mesmo com os altos investimentos na produção da amêndoa, e sendo o Brasil reconhecido pela qualidade do produto exportado, o setor vem passando por dificuldades. É possível verificar, através da Tabela 1, o grau de competitividade entre os principais países exportadores, o que acarreta redução do preço das amêndoas. ${ }^{7}$ Outro fator importante é a forte concorrência da Índia e Vietnã que dispõem de mão-de-obra de baixo custo. Tradicionalmente, a Índia é o maior produtor de amêndoas e emprega um processo manual com alto desempenho, sem produção do LCC; enquanto que no Brasil o processamento é semiautomático, com menor desempenho e geração de uma grande quantidade de LCC como subproduto.

No mercado internacional, o LCC tem sido adquirido para processamento do óleo e posteriormente revendido a preços elevados, e na produção de resinas e polímeros, como no caso da Cardolite Company $^{8}$ nos Estados Unidos e da Satya Cashew Chemicals ${ }^{8}$ na Índia, que oferecem produtos de fricção e materiais de revestimento. Por outro lado, os preços do LCC são muito variados e dependem exclusivamente da política adotada pelo cartel das multinacionais, oscilando a um valor médio irrisório quando se consideram suas potencialidades (Tabela 2). ${ }^{9}$
A queda no valor das amêndoas e o baixo custo da mão-de-obra nos países produtores concorrentes, atrelados à busca por fontes renováveis como matéria-prima alternativa à petroquímica, fazem da estratégia de valorização do LCC uma perspectiva bastante atrativa. A questão fundamental é: como e quais linhas de produtos podem ser empregadas para torná-lo competitivo? A resposta poderá mudar sensivelmente o quadro social e econômico do agronegócio tradicional do caju, em decorrência das maiores rentabilidades que poderão ser alcançadas com os derivados do LCC.

Na Itália, a Oltremare ${ }^{10}$ iniciou pesquisas nesse sentido, patenteando um processo de destilação para obtenção de um dos componentes do LCC, mas não está operando comercialmente. O Brasil traz excelentes resultados nessa vertente, alguns em parceria com instituições internacionais como é o caso do Laboratório de Produtos e Tecnologia em Processos (LPT) ${ }^{11}$ que, juntamente com as universidades de Lecce e Urbino (Itália), atrelados às diretrizes do Consórcio INCA, ${ }^{12}$ mantém um programa de cooperação internacional de importância acadêmica e industrial, baseada em Novos Materiais e Produtos da Química Fina Derivados do Cardanol. ${ }^{13-23}$

\section{COMPOSIÇÃO QUÍMICA DO LCC}

O LCC representa aproximadamente $25 \%$ do peso da castanha e é considerado um subproduto de agronegócio do caju, de baixíssimo valor agregado. Este líquido é uma das fontes mais ricas de lipídeos fenólicos não-isoprenoides de origem natural, cuja composição química principal pode ser vista na Figura 2. ${ }^{24-27}$ Possui diversas aplicações na química fina, de acordo com a funcionalização dos produtos isolados, ${ }^{13-23,28-38}$ aspecto que será discutido ao longo dessa revisão.

A Tabela 3 sumariza a composição média dos ácidos anacárdicos, cardanois, cardois e 2-metilcardois no LCC natural. ${ }^{39}$

Diferentes processos podem ser empregados para a obtenção do LCC: extração a frio (prensas), extração por solvente, ${ }^{40-42}$ processo térmico-mecânico (hot oil process) onde o próprio LCC quente é

Tabela 1. Evolução dos preços da amêndoa da castanha de caju no mercado internacional (US\$/kg)

\begin{tabular}{|c|c|c|c|c|c|c|c|c|c|c|c|c|c|}
\hline \multirow[t]{2}{*}{ Países } & \multicolumn{13}{|c|}{ Ano } \\
\hline & 1995 & 1996 & 1997 & 1998 & 1999 & 2000 & 2001 & 2002 & 2003 & 2004 & 2005 & 2006 & 2007 \\
\hline Brasil & 4,62 & 4,62 & 4,32 & 4,47 & 5,90 & 4,91 & 3,82 & 3,49 & 3,46 & 4,19 & 4,47 & 4,33 & 4,37 \\
\hline Índia & 5,47 & 5,26 & 4,92 & 5,10 & 6,19 & 5,12 & 4,06 & 3,25 & 3,66 & 4,69 & 4,68 & --- & --- \\
\hline Vietnã & 4,75 & 4,22 & 2,48 & 4,04 & 5,96 & 4,70 & 3,47 & 3,36 & 3,36 & 3,77 & 4,12 & --- & --- \\
\hline
\end{tabular}

Tabela 2. Quadro de exportação brasileira das amêndoas e líquido da casca da castanha

\begin{tabular}{|c|c|c|c|c|c|c|}
\hline \multirow[t]{2}{*}{ Ano } & \multicolumn{3}{|c|}{ Exportação de ACC } & \multicolumn{3}{|c|}{ Exportação de LCC } \\
\hline & US\$ FOB & $\begin{array}{l}\text { Qtde }(\mathrm{kg}) \\
\text { Líquido }\end{array}$ & Containers & US\$ FOB & $\begin{array}{l}\text { Qtde (kg) } \\
\text { Líquido }\end{array}$ & $\begin{array}{l}\text { Preço Médio } \\
\text { (US\$/kg) }\end{array}$ \\
\hline 2001 & 112.251 .250 & 29.356.397 & 1849 & 4.851 .105 & 19.508 .083 & 0,25 \\
\hline 2002 & 105.131 .659 & 30.114 .329 & 1897 & 2.063 .639 & 12.341 .151 & 0,17 \\
\hline 2003 & 143.759 .914 & 41.568 .892 & 2618 & 2.795 .985 & 18.147 .840 & 0,15 \\
\hline 2004 & 186.375 .523 & 47.441 .525 & 2988 & 4.096 .192 & 23.696 .135 & 0,17 \\
\hline 2005 & 187.126 .443 & 41.856 .059 & 2636 & 5.566 .157 & 35.986 .847 & 0,15 \\
\hline 2006 & 187.537 .640 & 43.231 .464 & 2723 & 4.753 .141 & 19.393 .350 & 0,25 \\
\hline 2007 & 225.194 .990 & 51.556 .489 & --- & 4.803 .619 & 19.464 .904 & --- \\
\hline $2008 *$ & 76.915 .068 & 14.782 .892 & --- & 3.231 .177 & 7.336 .900 & --- \\
\hline
\end{tabular}

* Média dos meses de Janeiro a Setembro/2008 
Tabela 3. Composição dos componentes fenólicos do LCC natural, com relação ao número de insaturações, obtida por CG/EM

\begin{tabular}{lcccc}
\hline Constituinte & Ácido anacárdico & Cardanol & Cardol & 2-metilcardol \\
\hline Saturado & $2,2-3,0 \%$ & $3,9-4,4 \%$ & $0,2-2,7 \%$ & $0,9-1,3 \%$ \\
Monoeno (8') & $25,0-33,3 \%$ & $21,6-32,2 \%$ & $8,4-15,2 \%$ & $16,3-25,3 \%$ \\
Dieno (8', 11') & $17,8-32,1 \%$ & $15,4-18,2 \%$ & $24,2-28,9 \%$ & $20,6-24,4 \%$ \\
Trieno (8', 11', 14') & $36,3-50,4 \%$ & $45,2-59,0 \%$ & $36,5-67,2 \%$ & $49,8-62,2 \%$ \\
\hline
\end{tabular}
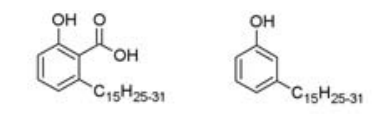

Ácido Anacárdico
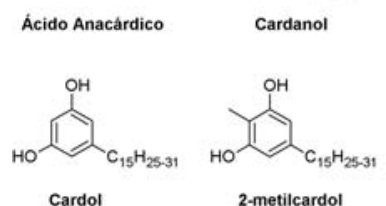

Figura 2. Principais constituintes do LCC

usado como meio para aquecer as castanhas in natura a aproximadamente $190^{\circ} \mathrm{C}$; nessa temperatura, a casca externa se rompe e libera os alquilfenois presentes na casca porosa (mesocarpo), seguido da remoção da casca interna, o que permite a recuperação das amêndoas ou, ainda, extração supercrítica com $\mathrm{CO}_{2}$, onde o rendimento é praticamente $100 \%$. $^{43}$

Quando submetido a altas temperaturas $\left(180^{\circ} \mathrm{C}\right)$, o ácido anacárdico sofre reação de descarboxilação convertendo-se a cardanol (Figura 3), produzindo o denominado LCC técnico. 26,27,29,30

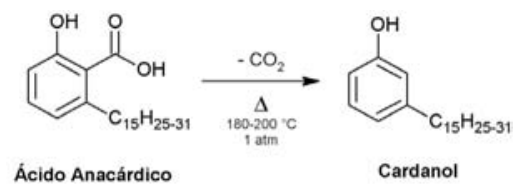

Figura 3. Processo de descarboxilação do ácido anacárdico

De acordo com Gedam, ${ }^{24}$ após determinações na composição química do LCC natural e técnico, foi constatada uma grande diferença na composição de ambos (Tabela 4). O LCC natural contém uma grande quantidade de ácido anacárdico e não apresenta material polimérico em sua composição. Entretanto, o LCC técnico mostrou um elevado percentual de cardanol e, também, material polimérico, presentes em todas as amostras analisadas.

Essa diferença pode ser melhor explicada considerando o processo industrial empregado no Brasil. Uma vez que a recuperação das

Tabela 4. Composição química do LCC natural e LCC técnico

\begin{tabular}{lcc}
\hline $\begin{array}{l}\text { Componentes } \\
\text { Fenólicos* }\end{array}$ & $\begin{array}{c}\text { LCC Natural } \\
(\%)\end{array}$ & $\begin{array}{c}\text { LCC Técnico } \\
(\%)\end{array}$ \\
\hline Ácido Anacárdico & $71,70-82,00$ & $1,09-1,75$ \\
Cardanol & $1,60-9,20$ & $67,82-94,60$ \\
Cardol & $13,80-20,10$ & $3,80-18,86$ \\
2-Metilcardol & $1,65-3,90$ & $1,20-4,10$ \\
Componentes Minoritários & 2,20 & $3,05-3,98$ \\
Material Polimérico & ---- & $0,34-21,63$ \\
\hline
\end{tabular}

*Os percentuais descrevem os limites inferior e superior empregando diferentes técnicas analíticas. Foram analisadas amostras novas, destiladas e envelhecidas. amêndoas é realizada unicamente para fins alimentícios, o processo térmico-mecânico empregado impõe a obtenção do LCC técnico como subproduto. A reação de descarboxilação durante o processo industrial é inevitável e, dessa forma, grandes quantidades de LCC técnico são produzidas. O processo de aquecimento contínuo acarreta no envelhecimento do óleo, promovendo reações de polimerização nos constituintes insaturados. ${ }^{39,44,45}$

\section{Agronegócio e a política de agregar valor aos subprodutos de biomassa}

Considerando a busca crescente por fontes renováveis e biodegradáveis, as potencialidades do parque industrial do agronegócio brasileiro, a grande quantidade de LCC técnico produzida no país e o elevado percentual de cardanol resultante dos processos industriais do LCC, é notório vislumbrar que uma das expectativas na busca de agregar valor a esse subproduto venha a ser o desenvolvimento de processo(s) de separação dos componentes do LCC. Essa vertente representa a promoção do desenvolvimento sustentável, suportada por uma autonomia tecnológica, pela obtenção de produtos de alto valor agregado aos derivados do LCC.

Dentro dessa estrutura de especialidades da indústria química, existe uma variedade de matérias-primas possíveis para utilização, obtidas unicamente de derivados do petróleo e carvão mineral. Na indústria moderna, esses mesmos derivados são baseados em fontes renováveis/biodegradáveis, e no Brasil esta se apresenta com uma dupla possibilidade, técnica e estratégica, possibilitando um desenvolvimento sustentável com autonomia tecnológica.

Inserido neste contexto, o cardanol torna-se um dos mais importantes e promissores componentes do LCC. Uma vez separado, pode ser empregado no setor da química fina, onde os preços dos produtos finais são elevados: aditivos, surfactantes, fármacos, pesticidas, dentre outros. Por ser um subproduto da indústria de castanha, qualquer melhoria (concentração e/ou separação) se caracteriza verdadeiramente como uma inovação tecnológica.

Em comparação aos derivados fenólicos similares, o cardanol apresenta peculiaridades em suas características químicas e físicoquímicas, especialmente no que se refere à posição da dupla ligação, o que permite inúmeras funcionalizações, além das usuais do anel fenólico (Figura 4), e características específicas a seus derivados (antioxidante, resistência à chama, hidrofobicidade). O cardanol não possui cheiro agressivo, apresenta baixa volatilização e ponto de ebulição mais alto que os demais compostos fenólicos derivados do petróleo, favorecendo assim a saúde de quem o manuseia e a do meio ambiente.

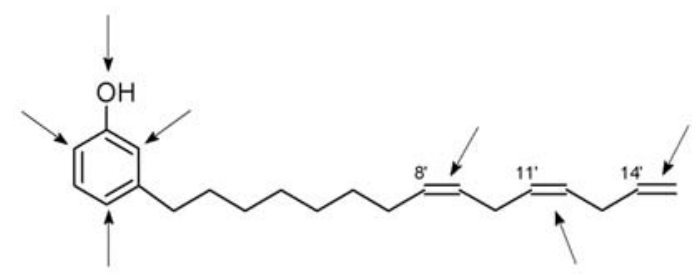

Figura 4. Principais sítios reacionais da molécula do cardanol 
A principal característica do cardanol puro como matéria-prima renovável e intermediário químico ecológico é a sua não-toxicidade. ${ }^{46}$ Testes realizados pela Organisation for Economic Co-operation and Development-OECD, uma das mais relevantes orientações acordadas internacionalmente para ensaios de produtos e métodos químicos, mostraram os seguintes resultados com relação à ecotoxicidade do cardanol: biodegradabilidade - 96\% (28 dias) - (OECD-302C); solubilidade em água igual a 1,0 g/L; ecotoxicidade $(96 \mathrm{~h})$ - peixe $<11$ $\mathrm{g} / \mathrm{L}$; dáfnias < $66 \mathrm{~g} / \mathrm{L}$; algas < 1 g/L - (OECD-425) e gen-toxicidade - negativo com testes empregando Ames salmonella.

Não menos importante, o cardol, presente em uma porcentagem de aproximadamente $18 \%$, é um dos constituintes menos estudados do LCC. Sua estrutura contém um sistema aromático similar ao do orcinol e sua longa cadeia carbônica na posição meta do anel aromático, desperta o interesse na sua utilização como substrato em síntese orgânica.

Apesar de inicialmente ter sido caracterizado como tóxico, ${ }^{47}$ estudos posteriores publicados por Suresh e Kaleysa Raj ${ }^{48}$ comprovaram tolerância de até $5 \mathrm{~g} / \mathrm{kg}$ em ratos. Foi observada ainda sua atividade antifilaríase, ${ }^{48}$ na inibição da acetilcolinesterase, ${ }^{49}$ contra o caramujo vetor da parasitose esquistossomose (Biomphalaria glabrata ${ }^{50}$ e do parasita Setaria digitata..$^{51,52}$

Diante dessas singularidades, é fácil perceber que a purificação dos constituintes do LCC é de grande interesse industrial. Vários processos têm sido relatados,,$^{53-60}$ mas vêm esbarrando nos baixos percentuais de cardanol puro, custo elevado dos reagentes e solventes envolvidos e frequentes contaminações com cardol e material polimérico, inviabilizando sobremaneira sua obtenção em larga escala.

Em escala laboratorial, o emprego da cromatografia em coluna permite a separação completa do cardanol dos demais componentes do LCC técnico. Entretanto, seu emprego industrial é economicamente inviável. Tyman ${ }^{53}$ foi o primeiro a promover a complexação dos compostos di-hidroxilados do LCC (cardol e 2-metilcardol) com dietilenotriamina, fornecendo $25 \%$ de cardanol e traços de cardol e de 2-metilcardol. Um aspecto desfavorável é o emprego de aminas (reagentes caros) e solventes com alta inflamabilidade.

Em 2002, Kumar $^{56}$ obteve rendimentos mais significativos de cardanol (45\%), utilizando uma única extração líquido-líquido, mas ainda com traços de cardol e de 2-metilcardol no produto final. Em 2004, Piyali ${ }^{57}$ adaptou o procedimento de Kumar, ${ }^{56}$ acrescido de uma etapa final de purificação em coluna cromatográfica, com $81 \%$ de rendimento de cardanol. Muito embora tenha mostrado resultados promissores, a descrição do autor é confusa e há limitação da quantidade de material empregado na coluna $(1 \mathrm{~g})$.

Oghome ${ }^{59}$ através do emprego de uma única coluna cromatográfica, conseguiu $23 \%$ de cardanol puro, mas o processo de purificação foi demasiadamente longo ( $28 \mathrm{~h}$ ), prejudicando o rendimento. Neste caso, os baixos rendimentos foram atribuídos ao excessivo tempo de permanência do material retido na coluna. Attanasi empregou sílica flash e reduziu o tempo de contato entre o adsorvente e o LCC, obtendo rendimentos expressivos de cardanol (70-80\%). ${ }^{60}$

Carneiro $^{61}$ realizou adaptações nos procedimentos de Tyman, ${ }^{52}$ Kumar, ${ }^{55}$ e Paramashivappa ${ }^{62}$ introduzindo uma purificação prévia em coluna cromatográfica, com intuito de remover o material polimérico. Não foi possível eliminar todo cardol e 2-metilcardol do produto final. Foram propostas ainda duas outras metodologias de separação por Carneiro, ${ }^{61}$ pelo emprego de microesferas de quitosana e quitosana reticulada, ambas atuando como agentes complexantes dos compostos di-hidroxilados do LCC. A metodologia foi eficaz na escala laboratorial, mas seu custo é alto em função da proporção de quitosana:LCC empregada (41:1).

Em 2007, o LPT ${ }^{11}$ investiu em um novo procedimento de separação dos constituintes do LCC técnico, empregando uma coluna mista de sílica gel e celite, com variação gradativa do eluente (éter de petróleo-metanol), de onde se obteve $70 \%$ de cardanol puro. ${ }^{28,63} \mathrm{O}$ processo apresentou vantagens em relação aos métodos anteriores, ${ }^{59-61}$ devido à menor relação adsorvente:LCC técnico, adequação do tempo do material na coluna e significativos rendimentos de cardanol.

Em escala industrial, ${ }^{10,41,64-66}$ o processo de destilação a vácuo mostrou ser uma alternativa interessante, mas permanecem as contaminações de cardol (4 a 6\%) e polímeros (10 a 15\%), como observado nos produtos oferecidos pela indiana Satya Cashew Chemicals ${ }^{8}$ e a italiana Oltremare. ${ }^{10}$ Patentes britânicas ${ }^{65,66}$ sugerem o emprego de aminas, como dietilenotriamina e $n$-butilamina na obtenção do cardanol puro. Nestas condições, o cardol forma uma base de Mannich mais reativa que o cardanol, separando-se do meio reacional.

De fato, a necessidade na melhoria do desempenho técnicoeconômico deste agronegócio exige uma nova e adequada abordagem no sentido da separação dos componentes do LCC e, sobretudo, sua utilização química efetiva no sentido de agregar valor a um subproduto de origem nacional, tão rico em funcionalizações e ainda muito pouco investigado dentro e fora do meio acadêmico.

\section{AVANÇOS, OPORTUNIDADES E SUSTENTABILIDADE}

A utilização do LCC e seus constituintes funcionalizados foram amplamente revisadas nas últimas décadas. ${ }^{24,28,33,67,68}$ Sua principal aplicação é na produção de derivados poliméricos e resinas, ${ }^{20}$ considerando seu potencial como possível substituto aos derivados do petróleo.

Os polímeros do LCC e do cardanol são obtidos pela policondensação com eletrófilos (formaldeído), pela polimerização das insaturações presentes na cadeia lateral (catalisadores ácidos) ou a partir de reações do grupamento hidroxila seguido de oligomerização, obtendo dessa forma pré-polímeros funcionalizados. Nesse aspecto, Bhunia e colaboradores ${ }^{69}$ publicaram a síntese de um monômero bifuncionalizado HPPDP (4-[(4-hydroxy-2-pentadecenylphenyl)diazenyl] phenol), (Figura 5a), a partir do cardanol, seguido de polimerização e formação de copoliester (Figura 5b).

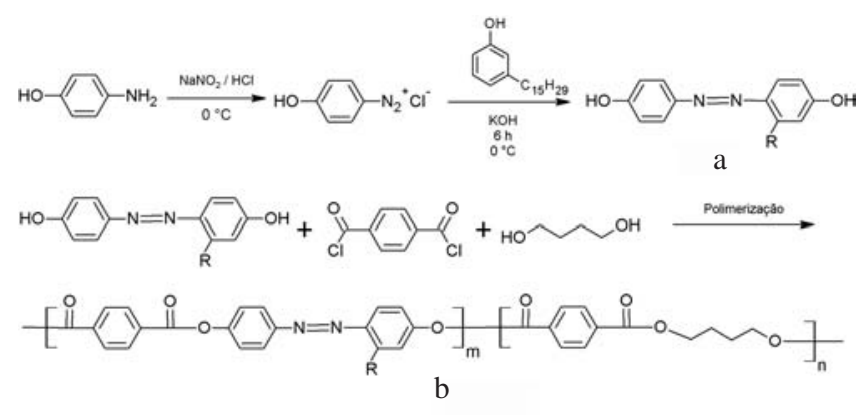

Figura 5. Síntese do copoliester a partir do monômero HPPDP

Dentre as principais utilizações desses polímeros destacam-se o uso em resinas de troca iônica, tintas anticorrosivas, materiais à prova d'água, retardantes de chama, no revestimento de superfícies, em materiais de atrito e na modificação de borrachas..$^{70-74}$ Polímeros com propriedades retardantes de chama são empregados na melhoria da resistência térmica de outros polímeros, dependendo basicamente de sua compatibilidade e miscibilidade.

Pré-polímeros fosforilados (Figura 6) também foram obtidos pela oligomerização do cardanol através das insaturações de sua cadeia lateral, ${ }^{75}$ cuja principal característica é seu comportamento como aditivos retardante a chamas, com compatibilidade em diversos plásticos e elastômeros como, polietileno (PE), policloreto de vinila (PVC), borracha natural, celulose e poliuretano. 


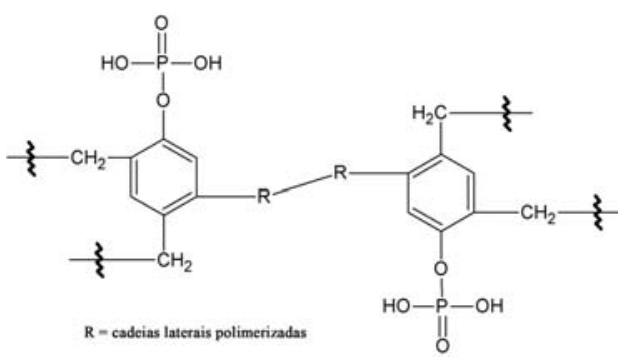

Figura 6. Pré-polímeros fosforilados do cardanol (PCP) retardantes de chamas

Diferente das demais resinas (alta rigidez), as obtidas a partir do LCC são mais maleáveis e mostram maior solubilidade em solventes orgânicos. Outro aspecto interessante é o seu caráter hidrofóbico, o que lhe confere resistência a bases e ácidos, propriedades decorrentes da presença da cadeia alifática de 15 carbonos na posição meta do anel fenólico. Sadavarte e colaboradores ${ }^{76}$ sintetizaram novas poli-imidas aromáticas solúveis em solventes orgânicos a partir de uma diamina derivada do cardanol hidrogenado, o que permitiu a formação de filmes transparentes e flexíveis em solução de clorofórmio (Figura 7).

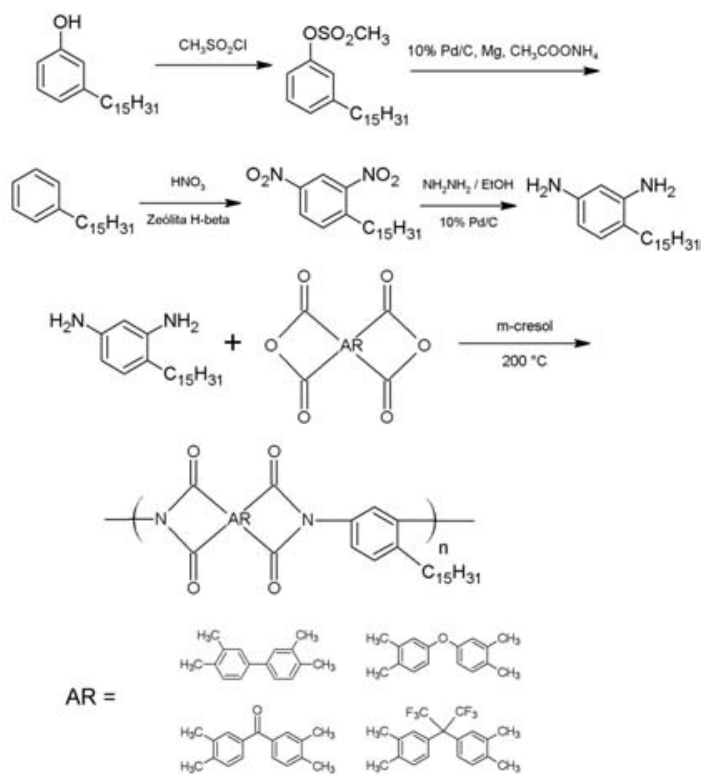

Figura 7. Síntese de poli-imidas aromáticas e seus polímeros

Na produção de biocompósitos, resinas termorrígidas do cardanol, reforçadas com fibras naturais, vêm sendo investigadas quanto às propriedades de superfície, biossorção, biodegradabilidade, dielétricas (permissividade, perda dielétrica e condutividade elétrica) e mecânicas. ${ }^{11,77}$

Estes materiais se apresentam como uma combinação inédita sob o ponto de vista da Química Verde, onde tanto a matriz precursora (cardanol) quanto as fibras vegetais, podem substituir em muitos aspectos as atuais matrizes fenólicas derivadas exclusivamente do petróleo. Os resultados demonstram uma interação eficiente entre matriz-agente de reforço, aumento nas propriedades mecânicas e aplicação potencial no emprego de isolantes para cabos, pequenos condensadores, apoio a sistema de energia em transformadores e motores elétricos.

Outra área em ascensão são os surfactantes derivados do LCC. Uma importante família de surfactantes não iônicos são os polietoxilatos baseados em alquilfenois, como os derivados do nonilfenol, caracterizados pelo baixo custo, alta eficiência e uso industrial e doméstico (Figura 8). Em função do acúmulo de poluição marinha provocada por essas substâncias, ${ }^{78}$ derivados polietoxilados do LCC foram investigados, o que resultou em uma patente com um novo composto, de detergência similar ao nonilfenol polietoxilado comercial e biodegradabilidade superior. ${ }^{79}$

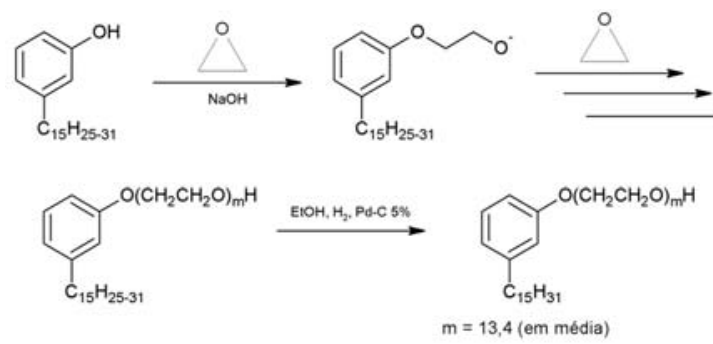

Figura 8. Síntese do surfactante cardanol polietoxilado por Tyman

Seguindo essa mesma linha, Peungjitton e colaboradores ${ }^{80}$ sintetizaram e analisaram as características físico-químicas de um novo surfactante sulfonado derivado do cardanol, comparando suas propriedades com as do surfactante comercial dodecilbenzeno sulfonato de sódio (DBS). Resultados de CMC (concentração micelar crítica), tensão superficial e detergência, fazem do cardanol sulfonato de sódio (CDS) uma possível alternativa comercial ao DBS (Figura 9).<smiles>Cc1ccc(S(=O)(=O)[O-])c(O)c1</smiles>

Figura 9. Surfactantes sulfonados sintetizados por Peungjitton e colaboradores

A hidrogenação catalítica do LCC também é pauta de investigação. ${ }^{13-19,22,23,27-30,39,45,81} \mathrm{O}$ cardanol hidrogenado (3-pentadecylphenol ou 3-PDP) e/ou seus derivados encontram aplicações, dentre muitas especificidades, como aditivos antioxidantes, ${ }^{25,27,29,45,82-86}$ principalmente nas indústrias de flavorizantes, estabilizantes, hidrorrepelentes, ${ }^{87}$ alimentos,${ }^{88}$ lubrificantes, polímeros e borrachas, ${ }^{39,84}$ além de acentuada atividade bactericida, ${ }^{24,31,89}$ fungicida ${ }^{24,90}$ e antitumoral. ${ }^{91}$

Nos últimos anos, a atividade antioxidante de derivados do cardanol hidrogenado foi reportada como comparável a produtos comerciais, no caso o 2,6-di-tert-butil-4-metilfenol (BHT) e o 2,6-di-tertbutil-4-metoxifenol (BHA). ${ }^{27,63,82,85}$ A síntese de novos derivados do cardanol é a chave para o desenvolvimento de aplicações industriais do LCC, assim como a concepção de novas drogas. Alquilação, ${ }^{31,92}$ acilação, ${ }^{31,93}$ tionação, ${ }^{31,87}$ nitração, ${ }^{31,86,94}$ halogenação, ${ }^{31,94} \mathrm{e}$ um grande número de outras transformações químicas têm sido avaliadas com o intuito da funcionalização seletiva do cardanol e demais componentes isolados do LCC.

Dessa forma, a química do 3-PDP mostra avanços interessantes nos últimos anos, principalmente no setor de antioxidantes, uma vez que sua estrutura fenólica favorece a aplicação como estabilizantes, além de permitir inúmeras funcionalizações na hidroxila. De acordo com a literatura, as moléculas mais utilizadas como antioxidantes são os fenois estericamente impedidos, as aminas aromáticas, alguns ésteres sulfitos, fosfitos e fosfatos, ${ }^{27,95}$ e os principais tipos de aditivos antioxidantes, eficientes contra a degradação de substratos orgânicos, são os sequestradores de radicais, os desativadores de metais e os decompositores de hidroperóxidos. ${ }^{27,95}$

Há exemplos recentes de sucesso na preparação de ftalocianinas, ${ }^{96}$ porfirinas, ${ }^{13,14,16-18}$ fulereno ${ }^{13,14,23}$ e derivados obtidos pelas reações de alilação e ciclocarbonilação do cardanol hidrogenado. ${ }^{87}$

A determinação da atividade antioxidante dos derivados do LCC, funcionalizados na oxidação térmica de filmes de cis-1,4-poli- 
isopreno, foi examinada por Rodriguez e colaboradores. ${ }^{97}$ Todos os materiais testados demonstraram um aumento no tempo de indução e redução nas constantes de velocidade.

A elevada atividade antioxidante encontrada para o LCC e cardanol, comparada aos demais funcionalizados, indica claramente a importância da insaturação. Baseado nesses resultados, os autores sugerem uma ordem crescente de atividade antioxidante: LCC $>>$ cardanol $=$ cardanol hidrogenado e alquilado $>$ cardanol hidrogenado.

Antioxidantes alquilfosforado e tiofosforado (Figura 10) também foram sintetizados a partir do cardanol hidrogenado, demonstrando claramente um aumento significativo na estabilidade termo-oxidativa dos óleos naftênicos NH10 e NH20 (aplicados como base para óleos isolantes e lubrificantes, respectivamente). ${ }^{83,84}$
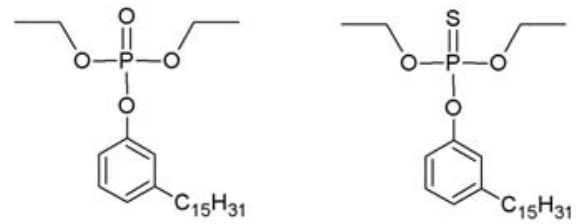

Figura 10. Antioxidantes alquilfosforado e tiofosforado derivados do cardanol hidrogenado

Dantas $^{85}$ e colaboradores exploraram os antioxidantes fenólicos sintetizados a partir do cardanol hidrogenado, via reação de FriedelCrafts. Os resultados mostraram-se satisfatórios quando comparados ao aditivo comercial parafenilenodiamina (PDE), largamente empregado nas refinarias de petróleo.

Ainda dentro da vasta área dos aditivos, os pertencentes à classe dos organofosforados vêm atuando como receptores de radicais livres. Fosfatos pentavalentes mostram excelentes aplicações em óleos lubrificantes, de compressor e retardantes a chama. ${ }^{26,98}$ Derivados fosforados do cardanol ainda são pouco explorados, por isso a grande relevância no sentido de contribuir nessa direção. Neste aspecto, ${ }^{11,45}$ uma série de compostos foram sintetizados, com o objetivo de verificar suas potencialidades como aditivos antioxidantes e de lubricidade, na aditivação de combustível diesel sintético e hidrorrefinado (Figura 11).
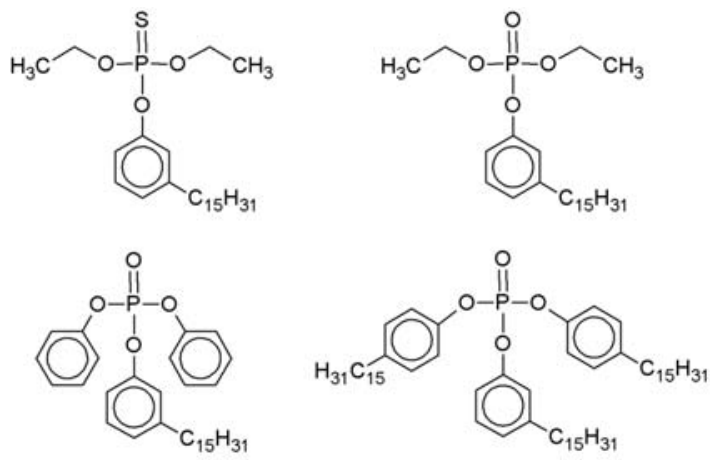

Figura 11. Adıtıvos antıoxldantes e de lubricıdade obtıdos a partır do cardanol hidrogenado

Os compostos mostraram uma temperatura inicial de degradação muito superior $\left(225\right.$ a $\left.315^{\circ} \mathrm{C}\right)$ à exigida pela câmara de combustão do motor (a partir de $120^{\circ} \mathrm{C}$ ), minimizando o atrito e o estresse gerados pelo contato das peças do motor, o que reflete diretamente na melhoria do desempenho e no tempo de desgaste das peças. A eficiência desses aditivos é notória quando adicionados ao diesel, em menor percentual de aditivação aos análogos comerciais. Os compostos também reduziram o desgaste nos óleos aditivados, característico da melhoria na capacidade de lubrificação pós-aditivação.
Eficientes aditivos de lubricidade implicam em uma série de vantagens: aumento na potência usando a mesma energia, melhoria na acomodação entre os anéis de pistão e as paredes do cilindro (melhor compressão), requer menos energia para dar partida nos motores, redução do calor gerado nas partes móveis em atrito e na emissão de gases poluentes, proteção das peças de contaminação do óleo por outros elementos (água, solvente, poeira), além de evitar que contaminantes se depositem nas superfícies metálicas (borras, carbonizações).

O mercado competitivo da indústria de aditivos requer compostos cada vez mais eficientes, os quais possam apresentar elevado desempenho em ensaios rigorosos. O mecanismo de ação dos aditivos de lubricidade derivados do cardanol é esquematicamente ilustrado na Figura 12. A parte apolar solubiliza o aditivo no combustível desejado, enquanto que a parte polar interage com os componentes metálicos do motor, formando um filme ou película que funciona como uma capa protetora, evitando o contato metal-metal, responsável pelos desgastes.

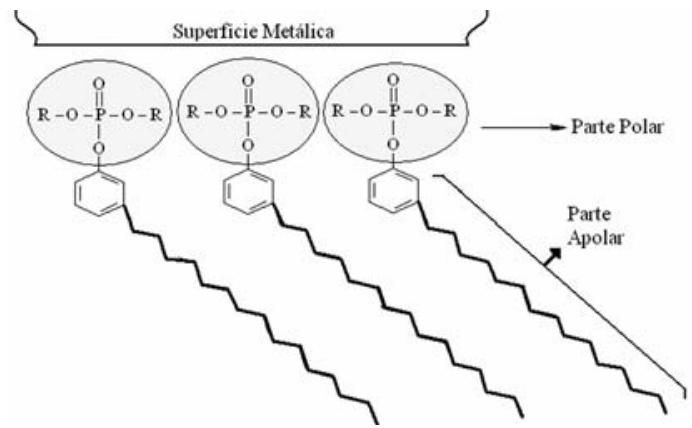

Figura 12. Ilustração da interação metal-aditivo de lubricidade

Rios $^{11,27,82}$ apontou preços competitivos no emprego de novas estruturas fosforadas derivadas do cardanol, quando comparados aos comerciais BHT e Irganox. Muitos produtos industriais requerem o uso de dois ou mais tipos de antioxidante para garantir sua estabilidade.

Dessa forma, $\operatorname{Rios}^{27,99}$ sintetizou aditivos multifuncionais: hidrogenado-fosforado, hidrogenado-alquilado-fosforado e hidrogenadoamilado-fosforado (Figura 13), o que potencializou suas funcionalidades e gerou estruturas com características decompositoras de peróxidos e capturadoras de radicais, com melhoria no desempenho em todas suas aplicabilidades, principalmente sob condições que envolvam altas temperaturas e alto estresse.

Outra característica privilegiada dessa classe de compostos é o fato destes se apresentarem na forma de óleo, facilitando a miscibilidade quando adicionados na aditivação e/ou demais aplicações, ao contrário dos análogos conhecidos no mercado, sempre encontrados na forma sólida.
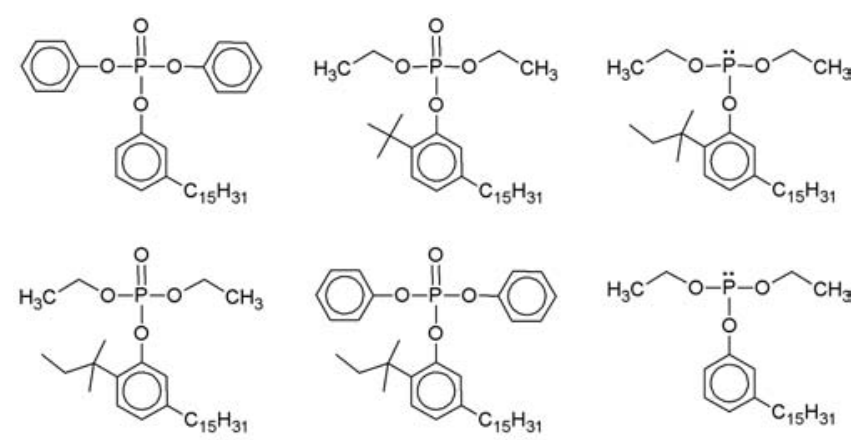

Figura 13. Aditivos multifuncionais derivados do cardanol 
O emprego dos constituintes do LCC como material de partida para síntese orgânica também tem sido alvo de diversos trabalhos. Lactonas e bis-lactonas foram preparadas a partir do cardanol, pelo emprego de métodos catalíticos de carbonilação (Figura 14). Os derivados foram facilmente sintetizados através de reações de ciclocarbonilação, utilizando acetato de paládio e 1,4-bis(difenilfosfina) butano (dppb) como sistema catalítico. ${ }^{87}$

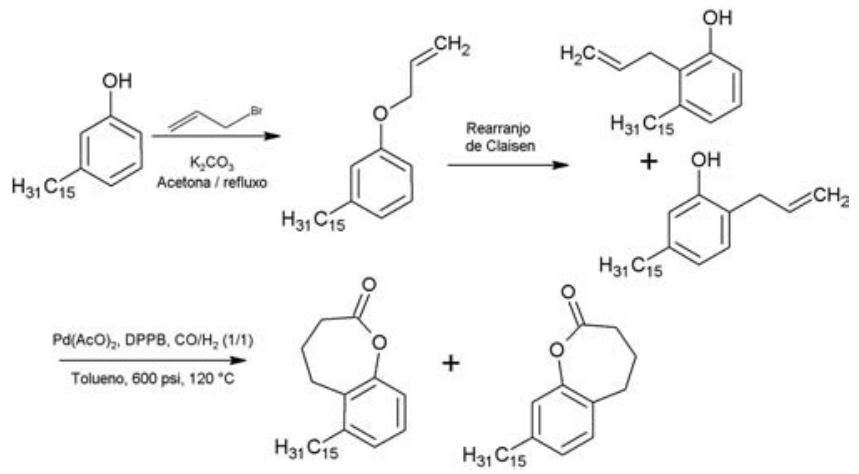

Figura 14. Síntese de lactonas a partir da ciclocarbonilação do cardanol

Reações de ciclocarbonilação também foram investigadas na preparação de novas benzoxazol-2-onas a partir de 5-npentadecil-2-nitrofenol, sob condições brandas e na presença do sistema catalítico $\mathrm{Pd}(\mathrm{OAc}) 2 / \mathrm{dppb}$, apresentando bons rendimentos (Figura 15). ${ }^{86}$

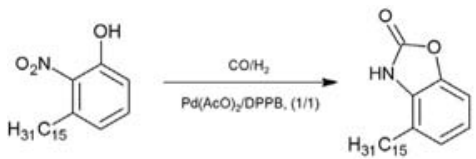

Figura 15. Síntese de benzoxazolonas a partir do cardanol nitrado

Fuleropirrolidinas derivadas do cardanol hidrogenado foram preparadas através de hidrogenação e posterior alquilação do anel aromático do cardanol. ${ }^{11,13,14,16-18,23,30} \mathrm{O}$ fulereno é um nanomaterial que continua a estimular avanços na ciência aplicada e fundamental, é um excelente aceptor de elétrons e pode ser quimicamente modificado para melhorar a solubilidade em solventes orgânicos..$^{14,23,100}$

Usualmente, a síntese de derivados fulerenos é realizada via condensação de aminoácidos ( $N$-metilglicina, $N$-fenilglicina) com um aldeído e $\mathrm{C}_{60}$, através de adição de ilídeos azometina gerados in situ. ${ }^{23,101}$ A Figura 16 ilustra a síntese em presença de um precursor aldeídico do cardanol.
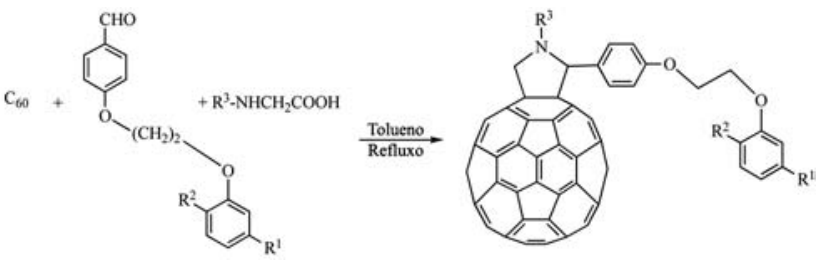

Figura 16. Sintese de derivados fulerenos a partir do cardanol

Porfirinas, ${ }^{11,12,14,16-18,30}$ ftalocianinas ${ }^{30,96}$ e moléculas macrocíclicas têm atraído a atenção devido as suas extensas aplicações em diferentes áreas, como novos materiais, tecnologia química, medicina, eletrônicos. Novas meso-tetra-arilporfirinas lipofílicas livres (Figura 17a) e metaladas (Figura 17b) foram sintetizadas a partir do cardanol e seus derivados. ${ }^{11,13,14,16-18,23,30} \mathrm{~A}$ longa cadeia lateral dessas porfirinas mostrou excelente solubilidade em solventes orgânicos, cerca de
100 a 300 vezes maior que as equivalentes não substituídas, além de menores pontos de fusão.

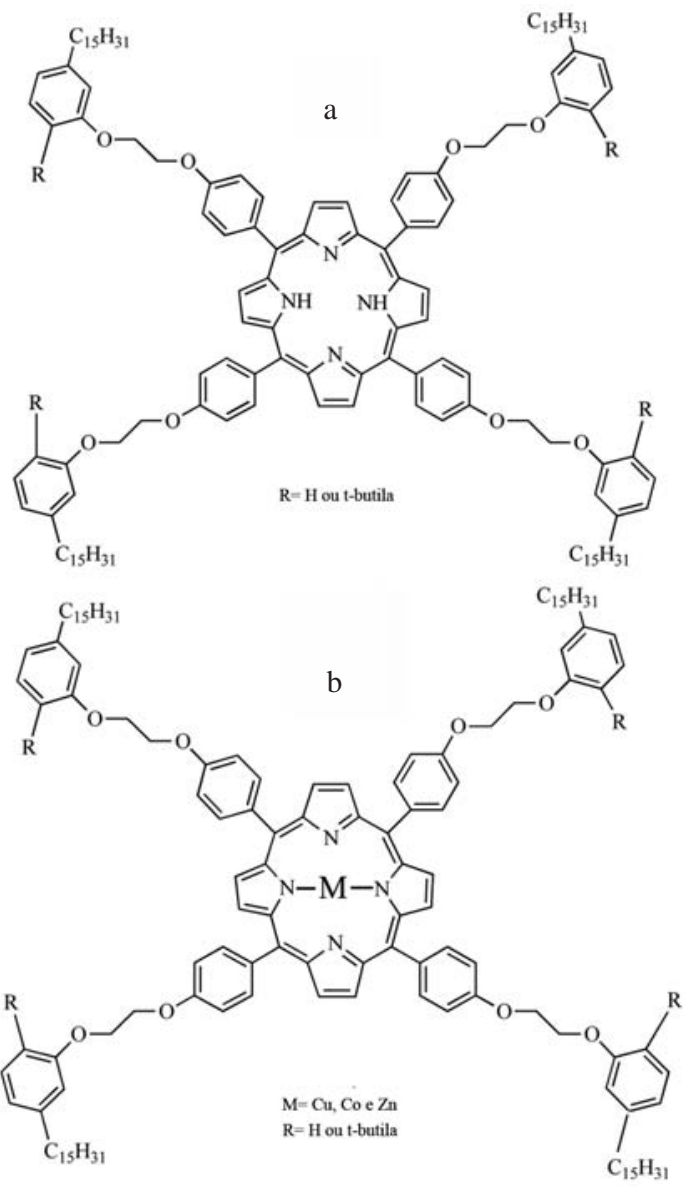

Figura 17. Porfirinas sintetizadas a partir do cardanol

Tendo em vista a reação de metátese de olefinas utilizando os catalisadores de Grubbs, uma série de compostos derivados do cardanol insaturado também foi obtida (Figura 18). ${ }^{37,102}$

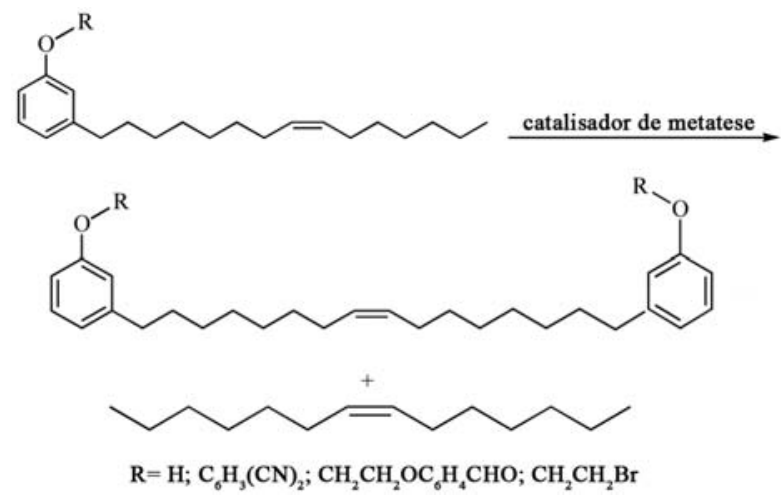

Figura 18. Derivados do cardanol via metátese de olefinas

O cardanol mostrou eficiência na síntese de sais de amônio quaternário. Três sais produzidos foram testados como catalisadores de transferência de fase em reações de oxidação e alquilação e apresentaram rendimentos próximos e/ou superiores aos das reações catalisadas por Aliquat (Figura 19)..$^{38}$

Uma parceria entre a Universidade Federal do Rio de Janeiro, a Universidade de Brasília e a Universidade Católica de Brasília comprovou, através de substâncias sintetizadas a partir do LCC, 


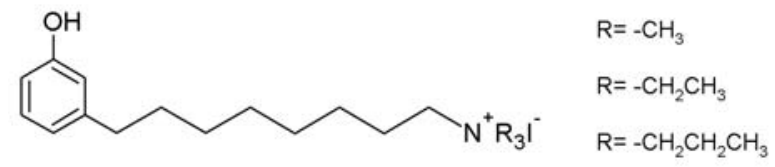

Figura 19. Sais produzidos para catálise de transferência de fase a partir do cardanol

propriedades que podem proteger a pele contra os raios solares. A invenção ${ }^{103}$ descreve derivados fenólicos não isoprênicos, obtidos a partir dos constituintes do LCC, capazes de absorver radiação ultravioleta UVA e UVB.

Ainda dentro desta parceria, estudos mais recentes com o cardanol e o ácido anacárdico geraram moléculas com poder de destruição de até $70 \%$ das células cancerígenas (câncer de mama) e de até $80 \%$ das células que provocam o câncer de boca. ${ }^{104}$

A síntese da lasiodiplodina, um macrolídeo orcelínico de 12 membros, de ocorrência natural, que exibe propriedade reguladora do crescimento de plantas e atividade antileucêmica, foi publicada por Santos e Magalhães a partir do cardol (Figura 20). ${ }^{56}$

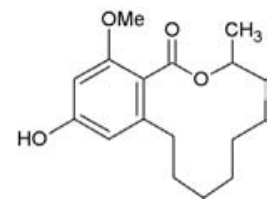

Figura 20. Lasiodiplodina sintetizada a partir do cardol

Recente publicação na revista Green Chemistry ${ }^{22}$ revelou resultados sobre a atividade larvicida contra o Aedes aegypti, empregando o LCC técnico, cardol, cardanol e seus análogos hidrogenados. A Tabela 5 apresenta os resultados dos bioensaios larvicidas ${ }^{105}\left(\mathrm{LC}_{50}\right.$ - índice de mortalidade larval) apontando excelentes resultados para o cardol, confirmando a importância das insaturações na estrutura do larvicida, responsáveis pela promoção da lipossolubilidade, que facilita sua passagem através da membrana celular. Os autores ${ }^{22}$ sugerem que o cardol poderá vir a ser considerado como o mais recente "larvicida verde" no combate à dengue.

Tabela 5. Valores correspondentes à mortalidade larval causada pelos componentes do LCC no combate ao mosquito Aedes aegypti

\begin{tabular}{lc}
\hline Amostra & $\mathrm{CL}_{50}(\mathrm{ppm})$ \\
\hline LCC técnico & $51,043 \pm 0,625$ \\
Cardanol & $28,903 \pm 0,365$ \\
Cardol & $14,202 \pm 0,626$ \\
Cardanol hidrogenado & $68,187 \pm 0,500$ \\
Cardol hidrogenado & $>500$ \\
\hline
\end{tabular}

\section{CONSIDERAÇÕES FINAIS}

A busca por fontes renováveis alternativas à petroquímica é hoje um sério problema que não só o Brasil, mas todo o planeta tenta superar. A alteração da matriz energética pela utilização de fontes renováveis representa um grande avanço para a economia e o meio ambiente. Nesse aspecto, o Brasil leva vantagem. Dados preliminares do Balanço Energético Nacional ${ }^{106}$ indicam que, em 2007, as fontes renováveis foram responsáveis por $46 \%$ da oferta energética no país, totalizando 111 milhões de tep (toneladas equivalentes de petróleo).
Entretanto, para que essa indústria emergente se desenvolva com eficiência e continuidade, é imperativo o investimento em competência tecnológica, isto é, em inovação, no desenvolvimento de produtos e processos e na produção biotecnológica e industrial. Como exemplo, podemos destacar inúmeros investimentos na geração de energia limpa através do aproveitamento da biomassa, porém, outra vertente pouco investigada desse processo, faz uso da biomassa na busca do aproveitamento de seus constituintes na produção de produtos de alto valor agregado - "química fina".

De acordo com Oliveira, ${ }^{107}$ o complexo industrial da química fina compreende intermediários de síntese (moléculas que atendem especificações técnicas), intermediários de uso (princípios ativos, medicamentos, defensivos agrícolas) e especialidades finais da química fina (produtos colocados no mercado consumidor). Nesse sentido, o LCC se enquadra como mais uma alternativa renovável em nosso país, junto ao etanol e o biodiesel, na substituição (ou diminuição) do uso dos derivados do petróleo.

Muito embora se conheça um grande número de produtos de altíssimo valor agregado, derivados do cardanol e cardol, o processo de separação desses constituintes em larga escala ainda continua sendo o principal gargalo para sua aplicação industrial. Em função do conhecimento das suas inúmeras potencialidades, diversos novos produtos devem surgir nos próximos anos, especialmente na área de surfactantes, polímeros e aditivos derivados do LCC. Outras áreas ainda permanecem pouco exploradas, especialmente as vinculadas às ciências biológicas e farmacêuticas, para a produção de materiais biologicamente ativos com aplicação como inseticidas, agrotóxicos e/ou medicamentos.

O cenário atual demonstra uma clara transição para processos mais avançados, que são vetores de transformação da biomassa, como a aquisição de conhecimentos, capacidades e competências, processos de tratamento e valorização de biomassa e resíduos, proteção do meio ambiente e desenvolvimento tecnológico. Esses desdobramentos contribuem significativamente para o desenvolvimento acadêmico e industrial de novas tecnologias.

Assim, as universidades e centros de pesquisa têm função primordial na busca por soluções que contribuam para o desenvolvimento tecnológico e sustentável, sem deixar de lado os aspectos sociais. O cenário mundial aponta que o desenvolvimento tecnológico vem crescendo e se aprimorando pela parceria entre os setores públicos e privados.

Essas parcerias geram tecnologias inovadoras que contribuem para a competitividade das empresas e países, e na formação de recursos humanos de elevada competência, capazes de acompanhar a velocidade das mudanças tecnológicas. Espera-se que os incentivos à inovação e à pesquisa científica, criados a partir da Lei da Inovação ${ }^{108}$ e seus desdobramentos, assim como a criação dos núcleos de inovação tecnológica nas IES's, possam estreitar e consolidar essas parcerias fortalecendo o desenvolvimento tecnológico e de inovação no país.

\section{AGRADECIMENTOS}

À CAPES, CNPq e Petrobras/CENPES pelos projetos aprovados abordando o LCC como tema central, assim como pelas bolsas concedidas e às Amêndoas do Brasil Ltda, pelo fornecimento do LCC.

\section{REFERÊNCIAS}

1. Pell, S. K.; Tese de PhD, Louisiana State University e Agricultural and Mechanical College, 2004; Blazdell, P.; Interd. Sci. Ver. 2000, 25, 220; Copeland, H. F.; Phytomorphology 1961, 11, 315; Roth, I.; Acta Biol. Venez. 1974, 4, 197; Ding, H.; Flora Malensiana 1978, 3, 395; Tyman, J. H. P.; Chem. Ind. 1980, 2, 59. 
2. Thévet, A.; Singularidades da França Antártica, Edusp: São Paulo, 1978.

3. http://www.ibge.gov.br/home/, acessada em Janeiro 2009.

4. http://www.sfiec.org.br/portalv2/sites/jornal/home.php?st=listinfo\& conteudo_id=5259; http://www.cajucultura.com.br/ex_ceara.html, acessadas em Dezembro 2008.

5. Shultes, R. E.; Raffau, F.; The Healing Forest. Medicinal and Toxic Plants of the Northwest Amazonia, Dioscorides Press: Portland, 1990; Smith, N.; Williams, J.; Plucknett, D.; Talbot, J.; Tropical Forests and their Crops, Comstock: Nova Iorque, 1992; Attanasi, O. A.; Buratti, S.; Filippone, P.; La Chim. e L'Ind. 1996, 78, 693.

6. http://revistavivasaude.uol.com.br/Edicoes/54/artigo63147-1.asp; http:// www.embrapa.br/imprensa/artigos/2005/artigo.2005-12-29.6574944222/; http://www.rain-tree.com/cajueiro.htm, acessadas em Janeiro 2009.

7. Secretaria do Comércio Exterior, Ministério do Desenvolvimento da Indústria e Comércio - SECEX/MDIC, 2008.

8. http://www.hoovers.com/cardolite/--ID_118730--/free-co-factsheet.xhtml; http://www.sccpl.com/,_http://www2spi.com/catalog/chem/labels/car. shtml, http://www.cardolite.com, acessadas em Dezembro 2008.

9. http://www.sindicaju.org.br/site/exportacao.html; http://www.desenvolvimento.gov.br/sitio/interna/interna.php?area $=5 \&$ menu $=1202 \&$ refr $=608$, acessadas em Janeiro 2009.

10. Oltremare Indústria Prodotti Alimentari e Derivati S.P.A.; IT Pat. 1,123,981, 1979

11. LPT - Laboratório de Produtos e Tecnologia em Processos (Universidade Federal do Ceará, Departamento de Química Orgânica e Inorgânica, Fortaleza - CE). Sob a coordenação da Profa. Dra. Selma E. Mazzetto, vem desenvolvendo suas atividades de pesquisa voltadas à produção de produtos e processos da Química Fina, que apresentem propriedades as quais justifiquem seus usos na Tecnologia Avançada de Materiais: aditivos, surfactantes, resinas, biocompósitos, biomateriais, metaloporfirinas, meso-porfirinas, catalisadores; norteados por uma política de agregar valor aos produtos derivados do LCC e seus constituintes, trabalhando em consonância com as legislações ambientais vigentes e na busca da sustentabilidade industrial.

12. INCA - Consorzio Interuniversitario Nazionale - La Chimica per l'Ambiente. O Consórcio tem como objetivo reunir grupos acadêmicos envolvidos com Química Fina e Meio Ambiente, direcionados na prevenção da poluição através da pesquisa em reações, produtos e processos mais limpos, desenvolvimento científico e tecnológico em todos os níveis, consolidação de conhecimentos, competências e formação de recursos humanos. Segundo o Consórcio, produtos derivados de biomassa (renováveis ou recicláveis) devem ser empregados sempre que possível.

13. Mazzetto, S. E., Relatório de Pós-doutorado, Universitá Degli Studi Di Lecce, Itália, 2002.

14. Attanasi, O. A.; Del Sole, R.; Filippone, P.; Ianne, R.; Mazzetto, S. E.; Mele, G..; Vasapollo, G..; Synlett 2004, 5, 799.

15. Attanasi, O. A.; Filippone, P.; Mazzetto, S. E.; Mele, G..; Vasapollo, G.; IV Convegno Nazionale sulla Scienza e Tecnologia dei Materiali, Ischia Porto, Italia, 2003.

16. Mele, G.; Del Sole, R.; Vasapollo, G.; Garcìa-Lòpez, E.; Palmisano, L.; Mazzetto, S. E.; Attanasi, O. A.; Filippone, P.; Green Chem. 2004, $6,604$.

17. Del Sole, R.; Mele, G.; Vasapollo, G.; Attanasi, O. A.; Filippine, P.; Mazzetto, S. E.; Third International Conference on Porphyrins and Phthalocyanines, New Orleans, Estados Unidos, 2004

18. Attanasi, O. A.; Del Sole, R.; Filippone, P.; Mazzetto, S. E.; Mele, G.; Vasapollo, G.; J. Porphyrins and Phthalocyanines 2004, 11, 1276; Guo, Y-C.; Xiao, W.; Mele, G.; Martina, F.; Margapoti, E.; Mazzetto, S. E.; Vasapollo, G.; J. Porphyrins and Phthalocyanines 2006, 10, 1071.

19. Calò, E.; Maffezzoli, A.; Mele, G.; Martina, F.; Mazzetto, S. E.; Tarzia, A.; Stifani, C.; Green Chem. 2007, 9, 754.
20. Kuhlmann, P.; Winter, R.; Priebe, C.; Pat. PI0214523-5, 2003; Simoneti, P.; Pat. PI0601256-6, 2006; Ferreira, J. C.; Visconde, L. L. Y.; Guimarães, P. I. C.; Pat. PI0403145-8, 2004.

21. Freitas, J. E. B.; Maffezzoli, A.; Mele, G.; Mazzetto, S. E.; Bioresour. Technol., submetido.

22. Lomonaco, D.; Santiago, G. M. P.; Ferreira, Y. S.; Arriaga, A. M. C.; Mazzetto, S. E.; Mele, G.; Vasapollo, G.; Green Chem. 2009, 11, 31.

23. Attanasi, O. A.; Mele, G.; Filippone, P.; Mazzetto, S. E.; Vasapollo, G.; Arkivoc 2009, viii, 69.

24. Gedam, P. H.; Sampathkumaran, ??; Prog. Org. Coat. 1986, 14, 115

25. Trevisan, M. T. S.; Pfundstein, B.; Haubner, R.; Wurtele, G.; Speigelhalder, B.; Bartsch, H.; Owen, R. W.; Food Chem. Toxicol. 2006, $44,188$.

26. Attanasi, A. O.; Buratti, S.; Fillipone, P.; Richmac Mag. 1996, Luglio/ Agosto: Attanasi, A.

O.; Fillipone, P.; Grossi, M.; Phosphorus Sulfur 1998, 35, 63.

27. Rios, M. A. S.; Tese de Doutorado, Universidade Federal do Ceará, Brasil, 2008.

28. Attanasi, O. A.; Beretta, S.; Favi, G.; Filippone, P.; Mele, G.; Moscatelli, G.; Saladino, R.; Org. Lett. 2006, 8, 4291.

29. Lopes, A. A. S.; Dissertação de Mestrado, Universidade Federal do Ceará, Brasil, 2005.

30. Mele, G.; Vasapollo, G.; Mini-Ver. Org. Chem. 2008, 5, 1.

31. Saladino, R.; Neri, V.; Mincione, E.; Marini, S.; Coletta, M.; Fiorucci, C.; Filippone, P.; J. Chem. Soc., Perkin Trans. 1 2000, 1, 581.

32. Moraes, S. M.; Rev. Bras. Farm. 1994, 74, 87.

33. Menon, A. R. R.; Pillai, C. K. S.; Nando, G. B.; Eur. Polym. J. 1998, $34,923$.

34. Amorati, R.; Pedulli, G. F.; Valgimigli, L.; Attanasi, O. A.; Filippone, P.; Fiorucci, C.; Saladino, R.; J. Chem. Soc. 2001, 2, 2142.

35. Pillot, J. P.; Birot, M.; Tran, T. T. T.; Dao, T. M.; Belin, C.; Desbat, B.; Lazare, S.; Langmuir 2005, 21, 3338.

36. Lu, S. Y.; Hamerton, I.; Prog. Polym. Sci. 2002, 27, 1661.

37. Guo, Y. C.; Mele, G. Martina, F.; Margapoti, E.; Vasapollo, G.; Xiao, W. J.; J. Organomet. Chem. 2006, 691, 5383.

38. Avellar, I. G. J.; Godoy, K.; Magalhães, G. C.; J. Braz. Chem. Soc. 2000, $11,22$.

39. Rodrigues, F. H. A.; Tese de Doutorado, Universidade Federal do Ceará, Brasil, 2006

40. Kumar, P. P.; Paramashivappa, R.; Vithayathil, P. J.; Subba Rao, P. V.; Rao, S.; J. Agric. Food Chem. 2002, 50, 4705.

41. Tyman, J. H. P.; Synthetic and Natural Phenols, Elsevier: Amsterdan, 1996.

42. Correia, S. J.; David, J. P.; David, J. M.; Quim. Nova 2006, 29, 1287.

43. Patel, R. N.; Bandyopadhyay, S.; Ganesh, A.; Bioresour. Technol. 2006, 97, 847.

44. Rodrigues, F. H. A.; Souza, J. R. R.; França, F. C. F.; Ricardo, N. M. P. S.; Feitosa, J. P. A.; e-Polymers 2006, 81, 1.

45. Oliveira, L. D. M.; Dissertação de Mestrado, Universidade Federal do Ceará, Brasil, 2007.

46. http://www.oecd.org/departament/0,3355,en_2649_34377_1_1_1_1_1,0 0.html,acessada em Dezembro 2008; USEPA, Test Plan for CNSL. High Production Value (HPV), Chemical Challenge Program, 2002; Test Plan for Cashew Nut Shell Liquid, Submitted to the US EPA by Cardolite Corporation Inc. 2002.

47. Wassernam, D.; Dawson, C. R.; J. Am. Chem. Soc. 1948, 70, 3675.

48. Suresh, M.; Kaleysa Raj, R.; Curr. Sci. 1990, 59, 477.

49. Stasiuk, M.; Bartosiewicz, D.; Kozubek, A.; Food Chem. 2008, 208, 996.

50. Kubo, I.; Komatsu, S.; Ochi, M.; J. Agric. Food Chem. 1986, 34, 970.

51. Tundo, P.; Rossi, R. H.; Química Verde en Latinoamérica, IUPAC: Buenos Aires, 2004.

52. Paiva, J. R.; Cardoso, J. E.; Barros, L. M.; Crisóstomo, J. R.; Cavalcanti, J. J. V.; Alencar, E. S.; Comunicado Técnico 78, Embrapa, 2002. 
53. Tyman, J. H. P.; Kiong, L. S.; Lipids 1978, 13, 525

54. Kiong, L. S.; Tyman, J. H. P.; J. Chem. Soc. Perkin Trans. 1 1981, 1, 1942.

55. Santos, M. L.; Magalhães, G. C.; J. Braz. Chem. Soc. 1999, 10, 13.

56. Kumar, P. P.; Paramashivappa, R.; Vithayathil, P. J.; Rao, P. V. S.; Rao, A. S.; J. Agric. Food Chem. 2002, 50, 4705.

57. Piyali, D.; Sreelatha, T.; Ganesh, A.; Biomass Bioenergy 2004, 27, 265.

58. Smith Jr., R.L.; Malaluan, R.M.; Setianto, W.B.; Inomata, H.; Arai, K.; Bioresour. Technol. 2003, 88, 1 .

59. Oghome, P.; Kehinde, A.J.; African J. Sci. Technol. 2004, 5, 92.

60. Attanasi, O. A.; Buratti, S.; Filippone, P.; P. Chim. Ind. 2003, 85, 11.

61. Carneiro, G. F. C. V.; Dissertação de Mestrado, Universidade Federal do Ceará, Brasil, 2005.

62. Paramahivappa, R.; Phani Kumar, P.; Vithayathil, P. J.; Srinivasa, R.; J. Agric. Food Chem. 2001, 49, 2548.

63. Rios, M. A. S.; Dissertação de Mestrado, Universidade Federal do Ceará, Brasil, 2004.

64. Harvey, M. T.; US Pat. 2,098,824, 1987.

65. Tyman, J. H. P.; Patel, M. S.; Manzare, A. P.; GB Pat. 2,066,820A, 1981.

66. Tyman, J. H. P.; GB Pat. 2,152,925A, 1985

67. Lubi, M. C.; Thachil, E. T.; Des. Monomers Polym. 2000, 3, 123

68. Tyman, J. H. P.; Chem. Soc. Rev. 1979, 8, 499.

69. Bhumia, H. P.; Nando, G. B.; Basak, A.; Lenka, S.; Nayak, P. L.; Eur. Polym. J. 1999, 35, 1713.

70. Chuayjuljit, S.; Rattanametangkool, P.; Potiyaraj, P.; J. Appl. Polym. Sci. 2006, 104, 1997.

71. Aggarwal, L. K.; Thapliyal, P. C.; Karade, S. R.; Prog. Org. Coat.2007, $59,76$.

72. Unnikrishnan, K. P.; Thachil, E. T.; J. Elast. Plast. 2008, 40, 271.

73. Ilomo, O. O.; Makame, Y. M. M.; Mkayula, L. L.; Bull. Chem. Soc. Ethiop. 2004, 18, 81 .

74. Bijwea, J.; Nidhib, N.; Majumdarb; Satapathya, B. K.; Wear 2005, 259, 1068.

75. Pillai, C. K. S.; Prasad, V. S.; Sudha, J. D.; Bera, S. C.; Menon, A. R. R.; J. Appl. Polym. Sci. 1990, 41, 2487.

76. Sadavarte, N. V.; Halhalli, M. R.; Avadhani, C. V.; Wadgaonkar, P.P.; Eur. Polym. J. 2008, doi:10.1016/j.eurpolymj.2008.11.013.

77. Mafezzoli, A.; Calò, E.; Zurlo, S.; Mele, G.; Tarzia, A.; Stifani, C.; Compos. Sci. Tech. 2004, 64, 839; Esmeraldo, M. A.; Dissertação de Mestrado, Universidade Federal do Ceará, Brasil, 2006; Barreto, A. C. H.; Dissertação de Mestrado, Universidade Federal do Ceará, Brasil, 2009.

78. Zoller, U.; Hushan, M.; Water Sci. Technol. 2001, 43, 245.

79. Tyman, J. H. P.; Bruce, I. E.; J. Surfactants Deterg. 2004, 6, 291; Ahmed, A. F.; Hart, G. L.; GB Pat. 2,262,525, 1993.

80. Peungjitton, P.; Sangvanich, P.; Pornpakakul, S.; Petsom, A.; Roengsumran, S.; J. Surfactants Deterg. 2008; DOI 10.1007/s11743-008-10826.

81. Changa, T. C.; Yua, P. Y.; Honga, Y. S.; Wub, T. R.; Chiub, Y. S.; Polym. Degrad. Stab. 2002, 77, 29; Prado, A. G. S.; Quim. Nova 2003, 26, 738; Kim, Y. H.; Won, K.; Kwon, J. M.; Jeong, H. S.; Park, S. Y.; An, E. S.; Song, B. K.; J. Mol. Catal. B: Enzym. 2005, 34, 33; Attanasi, O. A.; Filipone, P.; Balducci, S.; Gazz Chim. Ital. 1991, 121, 487.

82. Rios, M. A. S.; Leite, F.; Santiago, S. N.; Lopes, A. A. S.; Abreu, K. V.; Carioca, J. O. B.; Mazzetto, S. E.; Rev. Quim. Brasil 2007, 41; Rios, M. A. S.; Sales, F. A. M.; Mazzetto, S. E.; Fuel, submetido; Rios, M. A. S.; Alves, C.; Nascimento, T. L.; Santiago, S. N.; Mazzetto, S. E.; Fuel, no prelo.

83. Lopes, A. A. S.; Carneiro, E. A.; Mazzetto, S. E.; Rios, M. A. S.; Carioca, J. O. B.; Filho, J. J. H.; Barros, G. G.; Braz. J. Chem. Eng. 2008 25,1 .
84. Façanha, M. A. R.; Mazzetto, S. E.; Carioca, J. O. B.; Barros, G. G.; Fuel 2007, 86, 2416

85. Dantas, T. N. C.; Dantas, M. S. G.; Dantas Neto, A. A.; D’Ornellas, C. V.; Queiroz, L. R.; Fuel 2003, 82, 1465.

86. Attanasi, O. A.; Stefano, B.; Fiani, C.; Filipone, P.; Mele, G.; Saladino, R.; Tetrahedron 2006, 62, 6113.

87. Amorati, R.; Attanasi, O. A.; El Ali, B.; Filippone, P.; Mele, G.; Spadavecchia, J.; Vasapollo, G.; Synthesis 2002, 18, 2749; Attanasi, O. A.; Filippone, P.; Grossi, M.; IT Pat. 48737A/85, 1985; Attanasi, O. A.; Filippone, P.; IT Pat. 47920A/86, 1986; Attanasi, O. A.; Filippone, P.; IT Pat. RM93A000605, 1993; Attanasi, O. A.; Filippone, P.; IT Pat. PS95A000021, 1995; Coletta, M.; Filippone, P.; Fiorucci, C.; Marini, S.; Mincione, E.; Neri, V.; Saladino, R.; J. Chem. Soc. Perkin Trans. 1 2000, 581, Bhatnagar, A. K.; Verma, R. P.; Tuli, D. K.; Sarin, R.; Arora, A. K.; Ranjan, K.; Pat. PIO202545-0, 2002, Bhatnagar, A. K.; Tuli, D. K.; Sarin, R.; Parkash, S.; Kumar, S. K.; Pat. PI0102771-9, 2001.

88. Himejima, M.; Kubo, I.; J. Agric. Food Chem. 1991, 39, 418.

89. Morais, S. M.; Beezer, A. E.; Ashby, L. J.; Bolton, R.; Int. J. Pharm. 1990, 66, 107; Adawadkar, P. D.; El Sohly, M. A.; Fitoterapia 1981, 129; Chen, J.; Zhang, Y. H.; Wang, L. K.; Sucheck, S. J.; Snow, A. M.; Hecht, S. M.; Chem. Commun. 1998, 2769.

90. Fenner, R.; Betti, A. H.; Mentz, L. A.; Rates, S. M. K.; Rev. Bras. Cienc. Farm. 2006, 42; Adegeye, O. A.; J. Agric. Res. 2003, 4, 131; Araujo, C. R. F.; Pereira, M. S. V.; Higino, J. S.; Pereira, J. V.; Martins, A. B.; Arquivos em Odontologia 2005, 41, 193.

91. Short, E. L.; Tychopoulos, V.; Tyman, J. P. H.; J. Chem. Technol. Biotechnol. 1992, 53, 389; Morais, S. M.; Beezer, A. E.; Ashby, J.; Bolton, R.; Int. J. Pharm. 1990, 66, 107.

92. Baylis, C. J.; Odle, S. W. D.; Tyman, J. H. P.; J. Chem. Soc. Perkin Trans. 1 1981, 1, 132; Sancho, E. O.; Dissertação de Mestrado, Universidade Federal do Ceará, Brasil, 2005.

93. Tyman, J. H. P.; Lam, S. K.; J. Chem. Soc. Perkin Trans. 1 1981, 1942.

94. Attanasi, O. A.; Buratti, S.; Filippone, P.; Org. Prep. Proced. Int. 1995, 27,645 .

95. Denisov, E. T.; Oxidation and Antioxidants in Organic Chemistry and Biology, Taylor \& Francis Group; Flórida, 2005; Basfar, A. A.; AbelAziz, M. M.; Mofti, S.; Polym. Degrad. Stab. 1999, 66, 191.

96. Attanasi, O. A.; Ciccarella, G.; Filippone, P.; Mele, G.; Spadavecchia, J.; Vasapollo, G.; J. Porphyrins and Phtalocyanines 2003, 7, 52.

97. Rodrigues, F. H. A.; Feitosa, J. P. A.; Ricardo, N. M. P. S.; França, R. F. C. F.; Carioca, J. O. B.; J. Braz. Chem. Soc. 2006, 17, 265.

98. Pillai, C. K. S.; Prasad, V. S.; J. Appl. Polym. Sci. 2000, 77, 2631.

99. Rios, M. A. S.; Mazzetto, S. E.; BR Pat. PI0801708-5, 2008.

100. Vasapollo, G.; Mele, G.; Longo, L.; Ianne, R.; Gowenlock, B. G.; Orrell, K. G.; Tetrahedron Lett. 2002, 43, 4969.

101. Maggini, M.; Scorrano, G.; Prato, M.; J. Am. Chem. Soc. 1993, 115, 9798; Prato, M.; Maggini, M.; Acc. Chem. Res. 1998, 31, 519.

102. Mele, G.; Li, J.; Martina, F.; Margapoti, E.; Vasapollo, G.; Catal. Today 2009, 140, 37.

103. Romeiro, L. A. S.; Silva, V. C.; Murta, M. M.; Magalhães, G. C.; Logrado, L. P. L.; Santos, M. L.; Resck, I. S.; Moura, E. A.; DellamoraOrtiz, G. M.; Leitão, A. A. C.; Silva, C. S.; Freitas, Z. M. F.; Santos, E. P.; WO Pat. WO2006/042391 A2, 2006.

104. http://www2.mre.gov.br/cdbrasil/itamaraty/web/port/meioamb/biodiv/ divbio/chsecxxi/caju/index.htm, acessada em Março 2009.

105. Oliveira, M. F.; Mattos, M. C.; Lemos, T. L. G.; Segundo, T. A.; Santiago, G. M. P.; Braz Filho, R.; Ann Acad. Bras. Cienc. 2002, 74, 211.

106. http://www.mme.gov.br/site/menu/select_main_menu_item. do? channelId=1432\&pageId=15043, acessada em Março 2009.

107. Oliveira, N. B.; Quim. Nova 2005, 28, 79.

108. http://www.mct.gov.br/index.php/content/view/8477.html, http://www. mct.gov.br/index.php/content/view/8586.html, acessadas em Janeiro 2009. 